\title{
How Taiwanese Preschool Educators View Play and Apply It in Their Teaching
}

\author{
Chia-Yen Tsai ${ }^{1}$ \\ ${ }^{1}$ Department of Early Childhood Education, National Dong Hwa University, Taiwan \\ Correspondence: Chia-Yen Tsai, Department of Early Childhood Education, National Dong Hwa University, \\ Taiwan. Tel: 886-3-863-4896. E-mail: tsaicy@mail.ndhu.edu.tw
}

Received: October 10, 2016

Accepted: November 23, 2016

Online Published: March 30, 2017

doi:10.5539/ies.v10n4p152

URL: https://doi.org/10.5539/ies.v10n4p152

\begin{abstract}
In this research I investigated the views preschool educators in Taiwan on play and the role of play in the curriculum. Adopting a qualitative methodology, I conducted semi-structured interviews with 11 educators at preschools affiliated with elementary schools. The results indicate that preschool educators generally agree that, in addition to being a source of happiness for children, play also promotes learning and development. Thus play is seen as a meaningful learning activity which has a unique and valuable role in the preschool curriculum. However, the findings also indicate that participants need to give more attention to observing and understanding their children's abilities, interests, and developmental stages, so as to adopt a suitable role in various types of play and find the optimal balance between play and structured learning.
\end{abstract}

Keywords: play, preschool educators, teaching curriculum

\section{Introduction}

Play is an important experience for children because it is a dynamic process through which children actively explore the environment around them. Research findings have suggested there are positive physical, social, emotional, and cognitive outcomes associated with the opportunities to engage in play (Frost, Wortham, \& Reifel, 2012). Similarly, the revised third edition of Developmentally Appropriate Practice in Early Childhood Programs (Copple \& Bredekamp, 2009) makes clear, "Play is an important vehicle for developing self-regulation as well as for promoting language, cognition, and social competence" (p. 14). A fundamental principle within early years education is that play is essential for development and learning (Hirsh-Pasek, Golinkoff, Berk, \& Singer, 2009). Despite the existence of extensive research indicating the importance of play in early years education, the value of play is overlooked at many preschools. At present many parents in affluent societies such as England, the United States, and Hong Kong firmly believe in the concept of "early education," to such an extent that play is often seen as a waste of time and energy. As a result, the age at which children begin to feel academic pressure has steadily lowered. In such an environment, play time is often seen as expendable, making it increasingly difficult to make play an integral part of the curriculum (Rose \& Roger, 2012). Moreover, research has found that preschool teachers' views and attitudes about play, as well as the extent of their understanding of the relationship between play and learning, has a major bearing on how successful they will be in integrating play into the curriculum (Almy, Monighan, Scales, \& Van Hoorn, 1984). Furthermore, Trawick-Smith and Dziurgot (2010) found that teachers' understanding of play is strongly influenced by both their professional training as well as their personal beliefs and attitudes. Thus a study on how preschool educators integrate play into their teaching must necessarily take due account of their attitudes and beliefs about the role of play in preschool.

But just what is meant by "play"? While it may seem easy enough to understand what play is, it can be difficult to define. This is because play is an abstract concept, rather than a concrete form of behavior aimed at a specific goal, so designating a particular activity as play largely depends on how the activity is understood and structured by the participants (Johnson, Christie, \& Wardle, 2005). As a result, many scholars resort to explaining play by describing its unique characteristics in comparison with non-play activities, and then summing up the results. For instance, Garvey (1977) proposes that the best way to understand play is to start by determining what is not play, asserting that play and non-play can be differentiated in terms of the participants' underlying motivation. He also argues that one distinguishing feature of play is that it has no extrinsic motivations and that the participants freely choose to engage in it due to its intrinsic interest. Further, Rubin, Fein, and Vandenberg (1983) propose 
that the key characteristics of play are positive affect; intrinsic motivation; giving more importance to process as opposed to results; non-literality; freedom from external rules; and active participation. However, Rubin et al. (1983) also point out that it's preferable to merely specify the relative degree to which an activity conforms to the criteria of play being used, since such designations are always somewhat arbitrary.

Despite the variety of definitions, Bodrova and Leong (2003) point out that play is ordinarily comprehended as an important and valuable activity, and high-level play is perceived as both fun and developmentally valuable. Optimally, play in educational situations not only provides a real medium for learning and development, but also enables knowledgeable adults to learn about children and their needs. Unfortunately, it often happens that a hard and fast distinction is made between play and learning, whereby play is seen as spontaneously initiated by the participants themselves and not subject to external constraints, and learning is seen as a teacher-directed activity with specific goals, making it seem very much like "work." Ideally, teachers are skilled in combining educational goals and content with play and games to help their children acquire knowledge and skills. Adopting the three criteria of control, reality, and motivation, Sponseller (1974) explains a continuum that can be used to understand play from that which has the least amount of adult intervention to the most. In this spectrum, the intervals of play include free play, guided play, directed play, work disguised as play, and work. Similarly, Hoorn, Monighan-Nourot and Alward (2011) classify play into three types: spontaneous play, guided play, and teacher-controlled play. Thus it can be seen that there is general agreement that designating a learning activity as play depends on both child-centered factors (e.g., autonomy) and teacher-centered factors (e.g., the extent of teacher participation).

To be sure, some researchers do contend that it's not very meaningful to make a sharp distinction between work and play. For instance, Moyles (1994) argues that it's possible for a child to play while working and to work while playing, such that work and play are interconnected rather than absolutely discrete. For even though it may be necessary for a teacher to utilize structured learning activities which seem more like work than play, it's often possible to introduce various play-like elements into the activity to make it more spontaneous, variable, and enjoyable. Also, giving children more freedom to choose makes the activity seem more like play. Teachers can also find ways to encourage children to combine the materials found in different learning areas, design various lessons on specific themes, and encourage children to evaluate their own work, all of which tend to blur the distinction between work and play (Johnson et al., 2005). These are some of the ways to introduce the characteristics of play into non-play activities, enliven the learning environment, and increase children interest in learning. In addition, Siraj-Blatchford, Sylva, Muttock, Gilden, and Bell (2002) state that teachers should utilize play as a basis for instruction, thereby providing quality teaching and learning. However, teachers' perspectives on play are influenced by their own cultures, these perspectives differ widely (Izumi-Taylor, Samuelsson, \& Rogers, 2010). In Taiwan, "Curriculum Outline for Preschool Care-Taking Activities" published by Taiwan's Ministry of Education (MOE) in 2012 emphasizes independent, exploratory play, and encourages preschool educators to arrange and actively participate in a wide variety of interesting play activities. Preschool educators should provide play as the basic activity and the curriculum was designed that the child is placed at the centre of all teaching and learning activities (Ministry of Education, 2012). According to the policy, I felt that exploring preschool educators' perceptions of play could provide insights that might expand the discourse about play in Taiwan. Besides, there were no studies in Taiwan focusing on the relationship between play and curriculum. In light of the preceding, the goals of the present study were as follows: to determine the views and attitudes of preschool educator in Taiwan regarding play; to determine how they view the role of play in the curriculum; and to determine the ways in which they integrate play into their teaching. This study sought to provide some reflective matter to find out about preschool educators' beliefs and perceptions which promote or hinder a play-based curriculum. Moreover, the study will help policy makers to provide more training in play theories for preschool educators so as to be abreast with theories of play and play based pedagogy in development of children.

\section{Methods}

According to Yin (1994), for the purpose of investigating "how" and "why" questions, a qualitative research methodology are more suitable than a quantitative one. Moreover, interviews give participants an opportunity to share their experience, knowledge, and point of view (Hesse-Biber \& Leavy, 2006). Thus for this study I conducted semi-structured interviews with the participating preschool educators to determine their views on play, its relation to the curriculum, and its role in the teaching activities they conduct.

\subsection{Participants}

The participants in this study were 11 preschool educators recruited using the snowballing procedure. All the 
participants were female; their average age was 32.7 years. Six were fully qualified teachers, and five were educare givers. All had completed university, and some held master's degrees. At the time of the study all of the participants were teaching at preschools affiliated with an elementary school in Taiwan's Hualian County and had an average of three years of experience.

\subsection{Procedures}

The preschool educators participated in a one-to-one qualitative interview with the researcher. To avoid interruptions, the interviews were conducted in a quiet room at the preschool and recorded on audiotape (MP3). Each interview lasted between 60 and 90 minutes. Individual semi-structured interviews were conducted with the participants, providing both structure and flexibility to go into details in relation to the study (Bryman, 2004). Still, the introductory questions of the interview were questions about name, age, and if the preschool educators liked being in preschool. Patton (2002) advises not to start an interview with such boring questions, but the experience in this study was that preschool educators loved to talk about their daily experiences of interacting with children in preschool. These questions led to a mutual confidence between the participants and the researcher. In the rest of the questions included, for example: What do you think play is? What do you think children can learn from play? What do you think the relationship between the play and the curriculum? Can you tell me the role of play in the classroom? How do you integrate play into your formal teaching? Or what kind of play you provide in the formal teaching and why? Responses were sometimes followed up with further questions for clarification and exploration.

\subsection{Data Treatment and Analysis}

Semi-structured interviews were used to collect the data. The interviews focused on the participants' views and attitudes regarding play, how they view the role of play in the curriculum, and the ways in which they integrate play into their teaching activities. Each interview was recorded and transcribed. The primary data thus collected was organized, collated, and categorized. After the raw data was gradually refined in this way, I set about analyzing and interpreting it so as to uncover the salient themes and key findings. This process included repeated reading of the transcripts and a detailed analysis so as to identify all the meaningful statements having a significant bearing on the research topic. These statements gradually formed into categories and themes, which were systematically collated and conceptualized. Finally, the organized data was used to form a classification framework.

\section{Results and Discussion}

\subsection{Preschool Educators' Views on Play}

\subsubsection{Play as a Source of Joy and Autonomy}

Put simply, play is in children's live and children delight in play, especially self-directed play relatively free of external constraints. Lia noted," Play is a spontaneous sort of activity which brings happiness and joy." Yang said," Whatever you really enjoy doing, that's play; it's something you really like to do." Chen thought, "Kids get really excited about play because it's highly enjoyable." A theme of play associated with positive feelings was assigned when a response included reference to feelings of happiness, joy, excitement, enjoyment, or similar emotional states.

\subsubsection{Play as a Form of Learning}

Play is not only about having fun, but also an important learning medium. It's an instinctive form of behavior by which a child learns about himself, others, and the world. Play is characterized by curiosity, excitement, self-initiated exploration, and infinite variety. Thus, with appropriate adult input, play becomes a highly effective learning tool. Chen said, "Play is essentially the most direct way in which children learn. You don't have to teach kid's to play; they use play to learn of their own accord." Similarly, Lin described, "In addition to being a source of enjoyment, with the right guidance play can also be a way of learning and exploring. By playing different types of games, children actively try things out; this is a way of learning. The greater the variety, the more they learn; and learning and interest are mutually reinforcing." As an educator, it's essential to use play as a type of learning activity. Play has a very important role to play in education.

In addition to facilitating the acquisition of knowledge about the world and others, play promotes the development of a wide variety of important abilities, such as creativity and reflection. Thus play plays an essential role in childhood learning and development. Wu said," a kid is just like a sponge; everything in the external world has an influence on how a child develops. Play is the best way for kids to learn, since it stimulates development on various levels. When they play intellectual games, they enhance their creativity and reflective ability." 


\subsubsection{Play as a Basic Requirement of Children}

For children, play is a daily requirement, as important as food, water, and sleep. What's more, children don't need to be told or reminded to play, for the desire to play spontaneously arises from within. Undoubtedly, play brings a sense of satisfaction to body, mind, and spirit. Li said," play is a type of physiological need for kids, just like food and sleep. Kids get deeply immersed in play, and this promotes inner satisfaction and emotional stability." Lu described," As for kids, play is a natural daily activity, as important as eating and drinking." Play has a major role in the life of kids.

\subsubsection{Play as a Form of Exploring and Exercising the Imagination}

Play has no fixed form. Children are free to simply follow their imagination wherever it wants to take them in creating games and play themes of endless variety. Chou said, "Play is not limited to any particular form; kids are free to decide for themselves how they want to play; the possibilities are unlimited." Wu also alluded to creativity: "Play is a way of using the imagination to transcend reality; it's a kind of tool for stimulating creativity." Yeh noted, "While playing, kids use imagination to create new types of games and activities." Imagination is the internalization of children's play, which creativity exists when one's imagination combines, changes, and creates something new.

Nearly all the participating preschool educators agree that children derive a great deal of joy and satisfaction from play. In fact, many scholars of education see joy as one of the defining characteristics of play (Henricks, 2006; Shipley, 1998). Similarly, Levy (1977) describes playfulness as contributing to the unification of body, mind, and spirit. However, as for the other characteristics of play, there is a significant amount of variation, indicating the difficulty of formulating a precise definition of play, since much of the significance of play tends to vary from participant to participant (Johnson et al., 2005). Nonetheless, the participants indicated that they are convinced of the value of play in promoting their children's development, especially in regards to imagination, creativity, and cognition, as has been pointed out by Sutton-Smith (1997). If preschool educators focus on getting children to arrive at correct answers, they may discourage playfulness in the classroom and often reduce creativity (Izumi-Taylor et al., 2010).

\subsection{The Role of Play in the Curriculum}

\subsubsection{Play and Formal Instruction Are Different}

Some of the participants emphasized the differences between play and formal instruction, especially in terms of form, content, and objectives. This is mainly because play is seen as an autonomous activity, free of the normal constraints of time and space; by contrast, formal instruction is structured, has specific goals, and is normally directed by the teacher. Wu commented," If an activity is free of external constraints and the child is free to make all the choices - what to play, how to play, who to play with, and what things to play with - then it's play. If an activity has a theme and objective set in advance, and it's directed by the teacher, then it's formal instruction." $\mathrm{Lu}$ noted," I feel that play is different from formal learning. Formal learning has a specific objective and structure; it's carried out in a systematic way. By contrast, play is informal and can be engaged in at any time; it's a freely chosen activity."

3.2.2 Play and Formal Instruction Are the Same: Reaching Educational Goals by Integrating Elements of Play into Formal Instruction

Some of the participants see play and formal instruction as one and the same, since for them play constitutes an important element of their formal teaching. Wishing to make the most of children's strong interest in play, these teachers find ways to skillfully incorporate elements of play into various types of activities, thereby increasing children's motivation to participate and learn, and making their teaching more effective. Wang said," The teacher sets the learning objectives for the children, and hopes that they get it. There are all sorts of games that can be integrated into formal instruction." Yang noted, "A well-planned game is very effective for imparting certain types of understanding and helping the kids acquires various types of skills."

Many preschool educators thought that play is considered to be an important process that relates to children's learning and education. Su described, "Play is a kind of class in which the kids explore, gain experience, cultivate skills, and express their emotions. Play is an effective way to increase children's interest and participation." Lin extended this concept:" I find that play gets the kids more involved in the subject, because it's something they enjoy a lot, especially when they choose it themselves, rather than directly telling them to do it. Using play to guide them gets them more interested in the activity." 


\subsubsection{Play and Formal Instruction Are both the Same and Different}

Some of the participants said that sometimes play is a type of formal instruction, and other times it's not, depending on the amount of play elements the activity uses, and how they are regarded by the teacher and children. While teachers give more importance to the learning goals of an activity, seeing play as merely a medium of instruction, from the children's perspective it's the chance to freely play and explore without goals or adult interference that is most important. Lai noted, "They can be combined or separate. But in my view play is more important for kids than formal instruction. I feel that kids are capable of playing without adult guidance. By contrast, formal instruction is led by the teacher and has fewer play elements." Li also said, "If the activity is planned by the teacher in advance; guided by the teacher; uses set teaching materials; and has a specific goal, orientation, and content; then it's a class with some play elements." Similarly, Chou described, "Teachers see play as a kind of class; they introduce learning goals into the play, turning it into a kind of class the kids enjoy."

In fact, Johnson et al. (2005) point out three types of relationship between play and instruction: 1) play and instruction as completely separate; 2) play and instruction as coexisting, but not integrated; and 3) play and instruction as fully integrated. While these three types of relationships were also found in the present study, only the first was found in pretty much the same form; as for the latter two, there were some minor differences, mainly because the present study didn't investigate the degree to which of play and formal instruction are actually integrated. In the present study it was also found that many of the participants see play as an effective learning medium. This partially agrees with Hoorn et al. $(1993,2011)$, who assert that true integration of play and formal instruction means using play to help children learn concepts and acquire skills, what they term "curriculum-conceived play," whereby the teacher sets the goals and content of the activity, and then uses play to facilitate the children learning and development. Similarly, teachers lightly guide play, using play-based teaching and learning activities to facilitate curricular goals while maintaining the extremely important aspects of play — such as children's intrinsic motivation to engage in various kinds of play (Bordova, Germeroth, \& Leong 2013; Eberle, 2014).

\subsection{How Preschool Educators Integrate Play into Their Formal Teaching}

\subsubsection{Learning Areas}

Most of the participants' classrooms have designated learning areas provided with a variety of play materials. This is where the children engage in free play, in the process of which they learn various concepts and acquire a wide variety of skills. Thus the children's play in the learning areas also serves as an important supplement to formal instruction. Chou said, "Each learning area is designed to make the most of the educational benefits of play. While playing in the learning area, in addition to acquiring knowledge, the kids also develop their imaginations, creative abilities, and interpersonal skills." Su noted, "I feel that layout is quite important. For instance, arranging the doll area to look like a shop encourages the kids to pretend to be a shopkeeper selling something, and this helps them learn about numbers. Also, setting up a tea set in the life area encourages the kids to pretend to make and serve tea, and the like." This notion of learning area was further expressed by Li:" The learning areas are a place where learning and play go hand in hand. All that's necessary is to provide the appropriate toys and let the kids invent a new challenge for themselves; it also brings some interesting variety to the formal instruction. It's not necessary to directly tell them what to do; that would make it really boring."

Despite the existence of learning areas and set times for using them, during the interviews it was discovered that in general the children are only allowed to use them for free play once or twice per week, usually for only 30 or 40 minutes; it was also found that at some preschools they are mainly used for short transitional activities and that the allotted time coincides with the time for arriving in the morning. It was also found that some teachers consider making use of the learning areas during a formal class to be a form of play-learning. This approach is similar to that described by Chou (2013), in which play and formal instruction are seen as completely unrelated, such that play and toys are strictly reserved for after-class activities; it's also similar to that described by Rogers (2010), in which play is regarded as peripheral and mainly for amusement.

\subsubsection{Using Competitive Games to Stimulate Children Interest}

Some participants mentioned that they incorporate competitive games into their formal instruction as a way of increasing children participation and interest in a learning activity. Lu said, "I regularly design interactive activities which fit in with the teaching topic. I divide the kids into groups and organize a contest as a way of generating enthusiasm." Yeh noted, "It depends on the age group . . . with the older kids, competitive games are good for arousing interest."

Thus a number of participants were of the view that competitive games are a good way to enhance children 
interest in a subject and improve learning outcomes, as similarly pointed out by Johnson et al. (2005). However, it should be noted that with the games described by the participants, it seems that the rules were made by the teacher. Thus some might question how effective such a game is at generating children interest, and even whether it should be considered a game at all. This point was made by Fernie (1988), who states that if the rules are made by the teacher rather than by the participants, and when the tension of winning or losing is replaced by an adult's judgments of right and wrong, then it's not a real contest.

\subsubsection{Using Games for Teaching Anytime}

Some of the participants reported spontaneously adding play and games into various scheduled activities, sometimes as a way of helping the children settle down after arriving in the morning; sometimes as a way of generating interest in the topic being taught in a structured class; sometimes as a transitional activity; and sometimes even as part of snack time or outdoor play. Many incorporate lots of games into their formal classes in the expectation that this will make the instruction more effective. Chen described, "My teaching style includes lots of games. I find that games are a good way to get the kids motivated; sometimes various types of games are built into the lesson plan right from the beginning. The objective is to increase the kids' learning motivation, so that they don't find learning to be difficult, oppressive, or boring." Yang said, "Games and play can be adapted to pretty much any activity throughout the day. For instance, while handing out snacks I might turn it into a counting game. Also, when I want to get a kid's attention, I might refer to what he or she is wearing and turn it into a kind of sorting game. And when we're on the outdoor playground I might play a rock balancing game with them."

Thus it can be seen that for the most part the play and games were planned, initiated, and supervised by the participants, and that their children had very little say in the matter, which is very similar to the findings of Polito (1994). The participants are finding that play is more often an activity that is "scheduled" rather than integrated into the daily activities of the preschool (Björk-Willén \& Cromdal, 2009). Actually, as pointed out by Johnson et al. (2005), guided play is not merely a means of teaching a particular topic, but is rather a way of integrating play into the formal instruction, during the course of which the teacher gains a better understanding of the children by closely observing them. In the present study it was found that the participants generally agreed that play is of primary importance to early childhood development, and that they make opportune use of play and games in their formal teaching. However, for pretty much all of them the main concern is to use play to enhance children learning. Moreover, none of the participants mentioned designing a play activity based on children's needs and interests as determined by observing them during play activities. Nor did any of the participants mention the possibility of simply acting as a guide and facilitator of child-initiated play, which could then be developed into a teaching activity. This evidence would indicate that a lack of understanding of play, combined with a mistrust of child-led activities and reluctance to give children choice and control, results in an overreliance on teacher-directed activities with teacher s having control and choice, reflecting strong framing (McInnes, Howard, Miles, \& Crowley, 2011).

\section{Conclusion}

The preschool educator who participated in this study generally regard play as a basic requirement of early childhood, since play is enjoyable and also facilitates learning, creativity, and overall development. They see play as a meaningful activity with an important role to play in education, and thus make extensive use of play in a wide range of activities for the purpose of achieving various learning goals. And even though most of the play is teacher-directed, it is still quite effective at creating an enjoyable learning environment and promoting children interest, participation, and learning. On the other hand, though the preschool educators' use of play was to help children understand concepts being taught during teaching and learning, children were not given the enough play time to discover and explore things on their own.

While it's clear that the participants give much importance to play and make ample use of it in their teaching, the actual effectiveness of their efforts depends on the extent to which they are able to deeply reflect on the meaning and significance of play and how it fits into the curriculum. It also depends on their ability to use observation to gain a good understanding of children's interests, abilities, and levels of development, based on which it becomes possible for the teacher to adopt a suitable role in various types of play, whether spontaneous, guided, or directed. Such an approach to integrating play into the curriculum is essential for realizing excellent results. After all, play and learning are complex concepts that may be easily dismissed as separate, when rather they are deeply intertwined (Theobald et al., 2015).

This study provided some important findings about developing preschool educators' views and attitudes regarding play, how they view the role of play in the curriculum, and the ways in which they integrate play into 
their teaching activities. We recommend that preschool educators involve children in planning activities. It is suggested that listening children's perceptions of play as a basis for understanding may be helpful to preschool educators. In doing so, preschool educators can become key agents in challenging the established view of children as incompetent, dependent and childish. Rather than imposing their views of appropriate play upon their children. Thus it becomes easy for preschool educators to enter into children's play and to guide them towards learning outcomes. Finally, it also had several limitations. First, the research was conducted in Taiwan's Hualian County so it is difficult to generalize the results to other geographic areas. Further research in different parts of the Taiwan is needed. Second, the study relied on preschool educators' interviews for play. Therefore, further research should investigate whether they actually integrate play into the curriculum has long term effect on children's learning.

\section{References}

Almy, M., Monighan, P., Scales, B., \& Van Hoorn, J. (1984). Recent research on play: The teacher's perspective. In L. Katz (Ed.), Current topics in early childhood education (pp. 1-25). Norwood, NJ: Ablex.

Björk-Willén, P., \& Cromdal, J. (2009). When education seeps into 'free play': How preschool children accomplish multilingual education. Journal of Pragmatics, 41, 1493-1518. https://doi.org/10.1016/j.pragma.2007.06.006

Bodrova, E., \& Leong, D. J. (2003). The importance of being playful. Educational Leadership, 60(7), 50-54.

Bodrova, E., Germeroth, C., \& Leong, D. J. (2013). Play and self-regulation: Lessons from Vygotsky. American Journal of Play, 6, 111-123.

Bryman, A. (2004). Social research methods. Oxford: Oxford University Press.

Chou, S. H. (2013). Play vs. curriculum: The implementation of children's play. Psychological Publishing Co.

Copple, C., \& Bredekamp, S. (Eds.). (2009). Developmentally appropriate practice in early childhood programs serving children from birth through age 8 (3rd ed.). Washington, DC: National Association for the Education of Young Children.

Eberle, S. G. (2014).The elements of play: Toward a philosophy and a definition of play. American Journal of Play, 6, 214-234.

Fernie, D. (1988). Becoming a student: Messages from first settings. Theory into Practice, 27, 3-10. https://doi.org/10.1080/00405848809543324

Frost, J. L., Wortham, S., \& Reifel, S. (2012). Play and child development (4th ed.). Upper Saddle River, NJ: Prentice Hall/Merrill.

Garvey, C. (1977). Play. Cambridge, MA: Harvard University Press.

Henricks, T. S. (2006). Play reconsidered: Sociological perspectives on human expression. Urbana: University of Illinois Press.

Hesse-Biber, S. N., \& Leavy, P. (2006). The practice of qualitative research. London: Sage.

Hirsh-Pasek, K., Golinkoff, R. M., Berk, L. E., \& Singer, D. G. (2009). A Mandate for Playful Learning in Preschool. New York: Oxford University Press.

Hoorn, J. V., Nourot, B. S., Scales, B., \& Alward, K. (1993). Play at the center of the curriculum. New York, NY: Macmillan.

Hoorn, J. V., Nourot, B. S., Scales, B., \& Alward, K. (2011). Play at the center of the curriculum (5th ed.). New York, NY: Macmillan.

Izumi-Taylor, S., Samuelsson, I. P., \& Rogers, C. S. (2010). Perspectives of play in three nations: A comparative study in Japan, the United States, and Sweden. Early Childhood Research and Practice, 12(1), 1-12.

Johnson, J. E., Christie, J. F., \& Wardle, F. (2005). Play, development and early education. New York: Allyn and Bacon.

Levy, J. (1977). Play behavior. New York: Wiley.

McInnes, K., Howard, J., Miles, G., \& Crowley, K. (2011). Differences in practitioners' understanding of play and how this influences pedagogy and children's perceptions of play. Early Years: An International Research Journal of Research and Development, 31(2), 121-133. https://doi.org/10.1080/09575146.2011.572870 
Ministry of Education. (2012). Curriculum outlines for preschool care-taking activities. Taipei: Ministry of Education.

Moyles, J. R. (1994). Introduction. In J. R. Moyles (Ed.), The excellence of play (pp.1-12). Philadelphia, PA: Open University Press. https://doi.org/10.1080/0969908940010201

Patton, M. Q. (2002). Qualitative research \& evaluation methods (3rd ed.). Thousand Oaks, California: Sage Publications.

Polito, T. (1994). How play and work are organized in a kindergarten classroom. Journal of Research in Childhood Education, 9, 45-57. https://doi.org/10.1080/02568549409594952

Rogers, S. (2010). Powerful pedagogies and playful resistance: Role play in the early childhood classroom. In L. Brooker, \& S. Edwards (Eds.), Engaging play (pp. 153-165). Buckingham, UK: Open University Press.

Rose, J., \& Rogers, S. (2012). Principles under pressure: student teachers' perspectives on final teaching practice in early childhood classrooms. International Journal of Early Years Education, 20(1), 43-58. https://doi.org/10.1080/09669760.2012.664472

Rubin, K. H., Fein, G. G., \& Vandenberg, B. (1983). Play. In E. M. Hetherington (Vol Ed.), \& P. H. Mussen (Ed.), Handbook of child psychology: Socialization, personality, and social development (pp. 693-774). New York: Wiley

Shipley, C. D. (1998). Empowering children: Play-based curriculum for lifelong learning (2nd ed.). New York: Nelson College Publishing.

Siraj-Blatchford, I., Sylva, K., Muttock, S., Gilden, R., \& Bell, D. (2002). Researching effective pedagogy in the early years. Report number RR356. London: Department for Education and Skills.

Sponseller, D. (1974). A schema for play and learning. In D. Sponseller (Ed), Play as a learning medium (pp. 115-123). Washington, DC : National Association for the Education of Young Children.

Sutton-Smith, B. (1997). The Ambiguity of play. Cambridge, MA: Harvard University Press.

Theobald, M., Danby, S., Einarsdóttir, J., Bourne, J., Jones, D., Ross, S., . . Carter-Jones, C. (2015). Children's Perspectives of Play and Learning for Educational Practice. Education Sciences, 5, 345-362. https://doi.org/10.3390/educsci5040345

Trawick-Smith, J., \& Dziurgot, T. (2010). Untangling teacher-child play interactions: Do teacher education and experience influence "good-fit" responses to children's play? Journal of Early Childhood Teacher Education, 31, 106-128. https://doi.org/10.1080/10901021003781148

Yin, R. (1994). Case study research: Design and methods (2nd ed). Thousand Oaks, CA: Sage.

\section{Copyrights}

Copyright for this article is retained by the author(s), with first publication rights granted to the journal.

This is an open-access article distributed under the terms and conditions of the Creative Commons Attribution license (http://creativecommons.org/licenses/by/4.0/). 